\title{
Retratos de mulheres na colonização canadense: The King's Daughter ([1974] 2011), de Suzanne Martel - uma releitura crítica do passado colonial
}

\author{
Images of women in the Canadian colonization: The King's Daughters ([1974] 2011), \\ by Suzanne Martel - a critical rereading of the colonial past
}

\author{
Beatrice Uber* \\ Universidade Estadual do Oeste do Paraná \\ Cascavel, Paraná, Brasil.
}

\begin{abstract}
Resumo: A narrativa híbrida, de história e ficção, The King's Danghter (2011), da canadense Suzanne Martel, aborda, como tema principal, o fato histórico da vinda de algumas órfãs francesas para a Nova França, o atual Canadá, durante o século XVII. Essas mulheres que deixavam a sua terra natal - no contexto histórico - tinham por obrigação casar-se com colonizadores franceses e gerar filhos desses, ou até mesmo criar os que já eram existentes de um primeiro casamento. Na releitura ficcional do passado, a diegese do romance coloca em evidência os discursos da personagem-protagonista, a órfã Jeanne Chatel, e também apresenta figuras secundárias, como a órfã Marie du Voyer e outras, por meio de um narrador heterodiegético. Nessa perspectiva, descreve-se a difícil viagem marítima e os primeiros anos de adaptação das órfãs nas florestas canadenses, junto a seus maridos e filhos. Uma vez que essas personagens, configuradas como as órfãs francesas do século XVII, passavam a residir no novo território em desenvolvimento, do mesmo modo que na história, elas não podiam regressar à Europa e tinham consciência de que ali passariam o resto de suas vidas. Com base nesse contexto histórico e sua releitura ficcional, esse artigo tem o propósito de analisar a configuração dessas personagens femininas retratadas como órfãs francesas, conhecidas, historicamente, como "The King's Daughters". Ao efetuarmos tal leitura, objetivamos, também, evidenciar que essa obra se configura, pela forma como relê criticamente o passado, dentro da mais recente modalidade desse gênero híbrido: o romance histórico contemporâneo de mediação. Teóricos como Sharpe (1992), Runyan (2010), Fleck (2007; 2017), Zug (2016), entre outros, servem de subsídios à proposta apresentada.
\end{abstract}

Palavras-chave: The King's Daughter. Suzanne Martel. Literatura canadense. Romance histórico contemporâneo de mediação. História vista de baixo.

\begin{abstract}
The hybrid narrative, of history and fiction, The King's Daughter (2011), by the Canadian writer Suzanne Martel, addresses, as the main theme, the historical fact of the coming of some French orphans to New France, the actual Canada, during the seventeenth century. These women, who left their homeland - in the historical context - had the duty of marrying French colonists and bear their children, or even raise the ones from a previously existed marriage. In the fictional rereading of the past, the diegesis of the novel puts in evidence the statements of the protagonist, the orphan Jeanne Chatel, and also presents secondary characters, like the orphan Marie du Voyer and others, throughout a third-person narrator. In this perspective, it is described the difficult sea voyage and the first years of adaptation in the Canadian forests, along with their husbands and children. Once these young women, portrayed as French orphans in the seventeenth century, started to live in the new territory to be developed, the same way as in history, they could not return to Europe and were aware of the fact they would spend the rest of their lives there. Based upon this historical context and its fictional rereading, this paper has the objective of analyzing the configuration of these female figures, portrayed as French orphans, historically known as "The King's Daughters". When we achieve such reading, we also aim to highlight that this literary piece, due to the way it rereads the past critically, belongs to the most recent category of this hybrid genre: the contemporary historical novel of mediation. Authors like Sharpe (1992), Runyan (2010), Fleck (2007; 2017), Zug (2016), among others, are used as theoretical background for the paper presented.
\end{abstract}

Keywords: The King's Daughter. Suzanne Martel. Canadian literature. Contemporary historical novel of mediation. History from below.

* Mestra em Letras pela Universidade Estadual do Oeste do Paraná (UNIOESTE), Cascavel, Paraná, Brasil. Email: bea_uber@hotmail.com. 


\section{CONSIDERAÇÕES INICIAIS}

A narrativa híbrida The King's Daugbter' (2011), da canadense Suzanne Martel, tem como objetivo reler o episódio histórico da vinda de órfãs francesas para a Nova França, o atual Canadá, ocorrido durante o século XVII - no reinado de Luis XIV, mais especificamente, na década de 70 desse século. O relato ficcional é apresentado ao leitor pelo viés de um narrador heterodiegético, que expõe os discursos de Jeanne Chatel e Marie du Voyer, duas das órfãs retratadas no romance e destinadas à missão de povoar o novo território.

Segundo informa a voz narrativa, a personagem protagonista, Jeanne Chatel, perdeu os pais ainda quando era um bebê e passou a residir com o avô, Honoré Chatel. Na sequência dos episódios narrativos, descreve-se como a casa onde viviam é queimada, devido a algumas rixas pessoais e financeiras entre as figuras mais pobres e as mais ricas da região, e o avô da protagonista vem a óbito. Consequentemente, sem ter onde morar, a menina é levada, na continuação linear de ações relatadas, para um orfanato, onde passa a viver desde sua infância até o momento em que deve partir para Nova França. Ali, segundo evidencia o narrador, naquele acolhimento para órfãos, Jeanne é condicionada aos ensinamentos da Igreja Católica, aprendendo a rezar e se comportar como se esperava de uma pessoa do sexo feminino naquele século XVII - sendo submissa. Nesse ambiente, de acordo com a exposição narrativa, a protagonista se torna amiga de outra personagem: a também órfã Marie du Voyer.

O destino de ambas as personagens é seguir para a colônia em desenvolvimento, no Canadá ${ }^{2}$. Segundo o discurso romanesco - ancorado no fato histórico do século XVII -, a monarquia francesa estava enviando para sua colônia canadense órfãs para casar-se com os colonizadores brancos franceses e gerar muitos filhos desses. Assim, vemos que a diegese se fixa no evento histórico da saga dessas moças enviadas à colônia, que ficaram conhecidas como as "filhas do rei". Essa medida faria com que a monarquia francesa assegurasse a posse da terra.

$\mathrm{Na}$ releitura romanesca desse passado, a figura secundária, Marie du Voyer, de 15 anos, tem a tarefa de se casar com um primo distante que emigrou ao Canadá, cuja mulher e filho mais novo morreram num ataque dos nativos iroqueses, além de criar seus outros dois filhos. Entretanto, durante a viagem marítima, essa personagem se apaixona por um jovem comerciante de 20 anos, Jean Dauvergne, cujo pai possui negócios na cidade de Quebec. Por causa dessa paixão, Marie pede que a protagonista se case com esse pretendente seu, possibilitando-lhe viver o grande amor que sente pela personagem Jean Dauvergne.

Adiante, na narrativa, a personagem Jeanne, assume o lugar de Marie, quando chegam ao Canadá, e se casa com o primo da amiga. O noivo, Simon Rouville configurado como um colonizador e comerciante de peles de animais -, ao ser informado que Jeanne não é sua prima, não se mostra surpreso, apesar dela ter 19 anos de idade, que

\footnotetext{
${ }^{2}$ Embora a historiografia use o nome Nova França, a narrativa de Martel faz uso do nome Canadá.
} 
era já avançada para uma donzela. A personagem masculina apenas importa-se com o fato da sua futura esposa ser uma "filha do rei", pois sabia que essas tinham uma função a cumprir. Após o matrimônio, as duas personagens recém-casadas partem para VilleMarie, um vilarejo distante de Quebec, onde irão residir.

A protagonista, na sequência das ações narradas, conhece os dois filhos de Simon: Nicolas, de 5 anos, e Isabelle, de 3. A casa, descrita pela personagem, encontra-se deteriorada - queimada, com chão de terra e sem janelas - e precisa ser reconstruída. $\mathrm{O}$ narrador revela que, enquanto o esposo sai pelas florestas para conseguir peles de animais, Jeanne fica em casa com as crianças e Gansagonas, uma figura feminina apresentada como nativa que age sendo uma empregada e realiza trabalhos braçais. $\mathrm{Na}$ sequência dos eventos narrativos, a casa de Simon e Jeanne sofre dois ataques dos nativos iroqueses. Em ambos, a protagonista se mostra uma mulher resistente porque consegue salvar os filhos de seu marido e manter-se viva. Apesar das dificuldades enfrentadas, como o frio canadense e os ataques dos nativos da terra, a personagem sente-se feliz na nova terra e acredita ter realizado sua tarefa. Essa figura, retratada agora como mãe, não só cuida dos filhos do primeiro casamento do marido como, também, engravida com o intuito de gerar mais crianças para ele e à coroa francesa.

Enquanto que a personagem secundária, Marie du Voyer, não se sente feliz no Canadá e deseja muito regressar à França, a protagonista da narrativa, Jeanne Chatel, sente-se exaltada com sua família canadense e grata pela oportunidade de ter feito parte do programa "filhas do rei", no qual o monarca, representado pela figura de Luís XIV, despendeu uma grande quantia monetária para que as órfãs pudessem unir-se em matrimônio, ter sua própria família e um status melhor, alcançado pelo matrimônio.

\section{AS FILHAS DO REI - UMA PERSPECTIVA NO ÂMBITO HISTÓRICO}

A época da colonização do "Novo Mundo" foi marcada pelo fato de metrópoles colonizadoras europeias enviarem homens para dar início ao processo de ocupação das novas terras. Entretanto, com o passar do tempo, muitos desses desbravadores almejavam regressar a sua terra natal, pois se sentiam sozinhos e isolados de uma civilização organizada, conforme explica Marcia A. Zug, em Buying a bride: an engaging history of mailorder matches (2016, p. 11). Um dos critérios para tentar manter os colonizadores no território a ser conquistado foi possibilitar, também, o envio de mulheres para que eles tivessem companhia e formassem uma família. Essas figuras femininas eram, geralmente, brancas, virgens e de origem europeia; e os colonizadores contemplados com tal vantagem, em geral, estavam a serviço do rei em seus novos territórios.

A França, a título de exemplo, enviou para a Nova França, o atual Canadá, um grupo de mulheres para se casar que ficou conhecido como the filles $d u$ Ro $i^{3}$, em francês, e the King's daughters, em inglês. Acerca desse episódio histórico, ocorrido durante o século XVII, Zug (2016, p. 30) faz uma explanação sobre o período histórico no qual o programa

3Nossa tradução: "As 'filhas do rei.", 
"filhas do rei" esteve em destaque e, também, expõe o motivo pelo qual jovens mulheres foram arregimentadas. De acordo com a autora:

Between 1663 and 1673, nearly eight bundred Frenchwomen immigrated to New France as brides for the male colonists. Known as the filles du roi, or "King's daughters", these women were recruited to belp solve the colony's population problem. The colony had spent years of hoping to increase immigration, but most French perceived Canada as remote and dangerous and had no interest in immigrating. ${ }^{4}$ (ZUG, 2016, p. 30).

Perante essa situação de colonização, juntamente com a condição social de muitas órfãs na sociedade francesa daquela época, lugares como os orfanatos e acolhimentos foram considerados propícios para a seleção de mulheres que tivessem o desejo de imigrar para as colônias em desenvolvimento.

Os estudos de Aimie Kathleen Runyan, em Daughters of the King and Founders of a Nation: Les Filles du Roi in New France (2010, p. 33), mostram as origens dessas mulheres, oriundas de três categorias. A primeira delas são as moças que residiam no Salpêtrière Hospital, uma entidade mantida pelo governo francês e Igreja Católica, com diferentes alas para diversos residentes, como órfãs, prostitutas e outras pessoas marginalizadas pela sociedade. A segunda categoria são aquelas que residiam em áreas rurais e, geralmente, sabiam sobre o programa de envio de mulheres ao Canadá pelo padre, que rezava missa aos domingos. Entretanto, Runyan (2010, p. 51) explica que poucas jovens pertenciam a essa categoria porque a maioria das famílias de regiões rurais procuravam por pretendentes entre os conhecidos, gerando, assim, um acúmulo de terras e herança entre si. A terceira e última categoria, evidencia as moças de baixa nobreza, como aquelas provenientes de famílias grandes, mas que tinham pouco dinheiro para seus dotes. Assim, arranjar um casamento com um nobre que estava a serviço do rei, numa colônia distante, era uma opção vantajosa. Todavia, Runyan (2010. p. 53-54) adverte que esse número era pequeno: "Some of these women, approximately sixty, came from some of the best society of seventeenthcentury France."

De acordo com Zug (2016, p. 36), "the purpose of the filles du roi program was to prevent

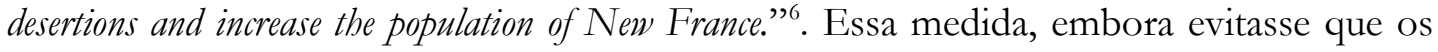
pioneiros abandonassem a colônia francesa para viver com as nativas da terra ou retornassem ao seu país de origem, também visava aos objetivos econômicos, como "dar um jeito" nas órfãs que viviam sob o custo do governo. Runyan (2010, p. 34) comenta

\footnotetext{
${ }^{4}$ Nossa tradução: "Entre 1663 e 1673, aproximadamente oitocentas mulheres francesas imigraram para a Nova França como noivas para os colonizadores. Conhecidas como filles du roi, ou 'filhas do rei', estas mulheres foram recrutadas para ajudar a resolver o problema de população na colônia. A colônia tinha passado anos tentando aumentar a imigração, mas a maioria dos franceses enxergava o Canadá como um lugar perigoso e remoto e não tinham interesse em imigrar."

${ }^{5}$ Nossa tradução: "Algumas dessas mulheres, aproximadamente sessenta, vieram da melhor sociedade francesa do século XVII.”

${ }^{6}$ Nossa tradução: "O propósito do programa das 'filhas do rei' era prevenir dissertações e aumentar a população da Nova França."
} 
que "sending these women, while costly, proved an efficient way of providing wives to the colonists and, in some cases, reducing the burden of women who were dependent on the state." 7

Uma das características atraentes desse programa para as jovens, tanto para as que se dispunham a fazer parte dele ou as que eram obrigadas a fazê-lo, era a possibilidade de escolher seu próprio marido. Conforme as pesquisas de Zug (2016, p. 41), "when the filles du roi agreed to immigrate, they were promised the right to chose their partner and the right to refuse any suitor." . Esse fato fez com que muitas jovens ficassem fascinadas pelo programa, que exigia delas, inicialmente, dois critérios: "women should be 'of ages suitable for procreation, and most of all that they be very healthy." (RUNYAN, 2010, p. 36). Posteriormente, mais duas características foram requeridas: "Attractiveness was added to the list, and experience performing bousehold chores." ${ }^{\prime 10}$ (RUNYAN, 2010, p. 36).

Para ser considerada uma "filha do rei" deveria, obrigatoriamente, haver algum subsídio por parte do governo que, segundo a pesquisadora Runyan (2010, p. 4), "while it is true that the majority of women who traveled to Canada between the years 1663 and 1673 received aid from the Crown, the form and quantity of this support varied greatly from immigrant to immigrant."11. Essa ajuda surgia tanto na forma de um enxoval, com itens para casa e outros pessoais, como também de forma monetária. O valor, conforme cita Zug (2016) em seus estudos: "Each bride received at least 50 livres, many received 100, and at least two women were given 600."12 (ZUG, 2016, p. 35).

Zug (2016, p. 43) explana, ainda, que quando essas "filhas do rei" já estavam casadas, também havia outra forma de ajuda financeira e incentivo para a procriação. Quanto mais filhos tivessem, mais dinheiro receberiam da monarquia francesa. Acerca disso, essa autora menciona que "the king instituted rewards to encourage large families. Specifically, Canadians with ten living children were entitled to a pension of three hundred livres annually, those with twelve living children four bundred." "13 (ZUG, 2016, p. 43).

Por fim, como indica Zug (2016, p. 44), as "filhas do rei" enxergavam a Nova França como um local de grandes oportunidades matrimoniais e, também, de grande independência feminina para a época.

\section{THE KING'S DAUGHTER (2011) - UM ROMANCE HISTÓRICO CONTEMPORÂNEO DE MEDIAÇÃO}

\footnotetext{
${ }^{7}$ Nossa tradução: "O envio dessas mulheres, que custou caro, provou ser um meio eficiente de providenciar esposas para os colonizadores e, em alguns casos, reduriu o fardo de mulheres dependentes do estado."

${ }^{8}$ Nossa tradução: "Quando as 'filhas do rei' concordaram em imigrar, prometeram a elas o direito de escolher seus parceiros $e$ o direito de recusar qualquer pretendente."

${ }^{9}$ Nossa tradução: "As mulheres deveriam estar em idade favorável à procriação, e principalmente serem muito saudáveis."

${ }^{10}$ Nossa tradução: "Belez̧a foi adicionada à lista, e experiência ao realizar as tarefas domésticas."

${ }^{11}$ Nossa tradução: "Enquanto que é verdade que a maioria das mulheres que viajou ao Canadá entre os anos de 1663 e 1673 recebeu ajuda da Coroa, a forma e a quantia dessa ajuda variaram muito de imigrante para imigrante."

${ }^{12}$ Nossa tradução: "Cada noiva recebia pelo menos 50 libras francesas, muitas recebiam 100, e pelo menos duas mulheres receberam 600."

${ }^{13}$ Nossa tradução: "O rei também instituiu recompensas para encorajar famílias grandes. Mais especificamente, canadenses com dez crianças vivas estavam intituladas a uma pensão de trezentas libras francesas anualmente, e aquelas familias com doze crianças vivas, quatrocentos."
} 
A ficcionista da narrativa híbrida em estudo retoma o tema das "filhas do rei" em sua produção romanesca. Quando a autora apresenta as personagens órfãs Jeanne Chatel e Marie du Voyer, ela faz uso de duas figuras que representam um grupo de indivíduos históricos: as "filhas do rei". Essas moças órfãs, retratadas de forma fictícia, fazem eco àquelas que a historiografia apresenta, também, como "the King's daughters".

Conforme Anatol Rosenfeld, em "Literatura e Personagem” (2007, p. 21), é “a personagem que com mais nitidez torna patente a ficção, e através dela a camada imaginária se adensa e cristaliza.". Assim, a configuração ficcional da órfã Jeanne, personagem-protagonista da narrativa de Martel (2011) permite que o leitor tenha a ideia do que as "filhas do rei" vivenciaram e quem eram essas moças. Sua figura, personagem de extração histórica - um termo proposto pelo estudioso André Trouche (2006, p. 44) e que é usado para fazer referência ao "conjunto de narrativas que encetam o diálogo com a história, como forma de produção de saber e como intervenção transgressora [...]"-, assemelha-se a enfermeira e freira francesa, Jeanne Mance, que deixou a França para fundar o Hôtel-Dieu em Montreal, local que no início da colonização era chamado como Ville-Marie. Embora a figura verídica tenha dedicado sua vida à igreja e não tenha se casado, ela convocou muitas jovens para viver no Canadá, sejam como freiras ou mulheres para o casamento.

Na narrativa The King's Daughter (2011), a personagem protagonista Jeanne Chatel, ao residir na colônia canadense, também se torna uma enfermeira e ajuda todos os residentes dentro de uma proximidade de vinte milhas. De acordo com o discurso fictício apresentado: "Jeanne learned to deliver babies, set fractured bones and, unfortunately, wrap the dead." 14 (MARTEL, 2011, p. 152).

A voz romanesca mostra a órfã retratada, Jeanne, logo no início do obra, como um exemplo atípico de "filha do rei". Quando foi levada ao orfanato, mostrou "a complete ignorance of the shorter catechism, basic prayers [...]"15 (MARTEL, 2011, p. 10), pois o avô, Honoré, havia-lhe ensinado assuntos que não pertenciam ao âmbito feminino da época na qual se passa a narrativa. Ela sabia sobre "Greek and Latin poets, the classic of the time, world history, the rudiments of arithmetic [...]". ${ }^{16}$ (MARTEL, 2011, p. 9). Temáticas como essas, que a personagem Jeanne tinha acesso, não eram permitidas às mulheres. Quanto menos conhecimento científico tivessem, mais controle sobre elas a Igreja teria, e, posteriormente, o marido também.

Outra peculiaridade de sua configuração é o fato de que tinha dezoito anos e não tinha parente algum que pudesse fornecer um dote para o seu casamento. Quanto mais o tempo passava, mais difícil ficava para essa personagem obter um marido. Além disso, "her education was a fiasco. She really could not be recommended as a model wife. She burned the pastry,

\footnotetext{
${ }^{14}$ Nossa tradução: "Teanne aprendeu a fazer partos, arrumar ossos fraturados, e, infelizmente embrulhar os mortos."

${ }^{15}$ Nossa tradução: "Uma ignorância completa sobre o catequismo, orações básicas [...]."

${ }^{16}$ Nossa tradução: "Poetas gregos e latinos, os clássicos da época, história mundial, os rudimentos aritméticos [...]."
} 
forgot to put on her cap, galloped through the hall, bounded down the stairs, and her proverbial carelessness was not even redeemed by a befitting sweetness." ${ }^{17}$ (MARTEL, 2011, p. 10-11).

A configuração dessa personagem mostra que, talvez, muitas daquelas moças que foram enviadas de fato à colônia não estavam aptas à sobrevivência e nem saberiam como fazê-lo. Se a protagonista não conseguia desenvolver habilidades culinárias no orfanato, seria quase impossível que ela as desenvolvesse na colônia canadense, onde tudo era mais escasso. Ademais, o envio da figura de Jeanne - moça já em idade avançada para o casamento e sem dote - coloca em destaque, pela ficção, a solução de sua situação social e econômica, já que seria difícil para um pretendente abrir mão do seu dote. Impossibilitada de conseguir na França um bom casamento e com uma péssima educação - aos olhos das freiras que tentavam ofertar alguma educação à órfã -, seu envio ao Canadá era o melhor recurso.

No entanto, o programa monárquico, que exaltava essas figuras de "linhagem real", não destacava que a origem das mulheres enviadas à colonização não passava, na maioria, de órfãs depreciadas e, muitas vezes, sem propensão para lidar com situações inesperadas, como a falta de comida e os ataques por parte dos nativos. Saber rezar, cozinhar e ser virgem nessas horas não valia de muito.

A protagonista da narrativa de Martel, Jeanne, ao deixar a França, sentia-se exaltada por fazer parte do programa de envio de moças para casar. Segundo seu discurso: " $A$ KING'S daughter! I'm a King's daughter!'18 (MARTEL, 2011, p. 7). Essa fala não apenas denota a alegria da personagem como, também, apresenta um status social, de repente, elevado. Sua condição de marginalizada é então transformada. Os termos utilizados, pela autora da obra, em caixa alta mostram uma proximidade com o monarca. As órfãs representadas ficcionalmente, como Jeanne e Marie, deixam de ser um encargo do estado para se tornarem parte da "família real". Assim, o destino dessas jovens é modificado quando ocorre essa proximidade com o monarca e o programa de inserção dessas jovens nas novas terras anexadas a seu reino. Um discurso exaltador emana da voz da protagonista.

Entretanto, quando a narrativa evidencia a chegada à colônia, a personagem percebe que esse é um local rudimentar, ainda por ser estruturado, e passa por dificuldades. Seus papéis são o de ajudar a edificar aquela terra, que pouco tem a oferecer. Como no orfanato, segundo o discurso do narrador, as internas aprendiam a rezar e a bordar, essa é uma das qualidades da personagem Jeanne e isso é o que ela tem, a princípio, a oferecer ao Canadá. Por exemplo, numa cena em que a personagem Simon Rouville - marido de Jeanne - entrega-lhe os filhos, Nicolas e Isabelle, e lhe ordena que compre roupas para as crianças, que estavam mal vestidas, ela não sabe como agir. Essa tarefa se torna impossível de ser cumprida, já que nas florestas canadenses não existia nenhum tipo de comércio ou loja que vendesse roupas. Todos os produtos eram manufaturados. No entanto, a protagonista não se deixa abater pela ordem do esposo e sua insensatez, já que é bem

\footnotetext{
${ }^{17}$ Nossa tradução: "Sua educação era um fiasco. Ela realmente não poderia ser recomendada como um modelo de esposa. Ela queimava tortas, esquecia de colocar sua toca, galopava pelos corredores, saltava pelas escadas, e sua falta de cuidado com os provérbios não era nem um pouco redimido pela sua própria docura."

18Nossa tradução: "Uma filha do REI! Eu sou uma filha do rei!"
} 
visível o não estabelecimento de comércio no local, impossibilitando a aquisição de itens. Porém, ela consegue ajuntar algumas vestimentas entre os moradores do forte e usa sua habilidade para a costura de algumas peças. Sua atitude mostra uma figura feminina decidida a superar qualquer dificuldade que se coloque em seu caminho, porém, seus relatos e ações mostram aos leitores que a vida no Canadá era bem diferente do que se esperava. A falta de produtos e a forma como viveriam ali na colônia canadense não era retratada pelo programa que a trouxe até ali, e sim, apenas a beleza do fato em ser uma "filha do rei" era divulgado e exaltado. Assim, tons de crítica ao programa monárquico começam a aparecer no discurso romanesco.

Ao longo da narrativa há outro momento no qual a protagonista, Jeanne, se transforma numa mulher determinada. Quando a criança mais velha, Nicolas, consegue arranjar um cachorro, a protagonista não pergunta ao marido sobre a possibilidade da criança ter esse animal de estimação. Quando o cônjuge olha assombrado para o bicho, ela se encoraja e deixa sua submissão feminina de lado, enfrenta a figura representada como esposo e toma partido da criança, inventando uma desculpa que não permite o mesmo retrucar: "Nicolas, did you thank the captain for bis gift? Keep the dog next to you." 19 (MARTEL, 2011, p. 107). Simon entendeu que seu poder sobre a esposa havia diminuído, pois seu discurso proferido foi: "God preserve me', he grumbled under his breath. T've married a shrew." 20 (MARTEL, 2011, p. 107). Nuances do fazer feminino começam a tomar vulto na narrativa, que revela, assim, outro lado, esquecido, da colonização: a grande contribuição direta dessas mulheres na edificação da nação.

De acordo com a ideologia da época, século XVII, esperava-se que a mulher acatasse as ordens do marido, que após o casamento, agia como seu dono. Se antes o discurso romanesco evidenciava uma personagem feminina submissa à Igreja, essa figura se transforma após o matrimônio e encontra mais liberdade para agir por conta própria, evidenciando, assim, o Canadá, local ficcional onde se passa a narrativa, como um território onde havia menos controle sobre seus habitantes, inclusive sobre as mulheres.

Ao longo das ações narradas, quando as dificuldades são superadas, como o armazenamento de comida para o inverno e a organização da casa com camas, mesa e cadeiras, Jeanne dá a luz a uma menina que é chamada de Honorine, cujo nome indica uma homenagem ao avô falecido. Depois dessa criança, a personagem tem a intenção de gerar mais filhos, cumprindo sua tarefa instituída pela monarquia francesa, como expressa numa carta, posteriormente, enviada à amiga Marie: "When we have another daughter, she will be baptized Marie, in honour of you. And the next ones will be Marguerite, Anne and Geneviéve. Oh, I've got a of work ahead of me."21 (MARTEL, 2011, p. 230).

Parte dessa sua escrita - destacada em negrito como nosso grifo -, numa carta que estava destinada a personagem Marie, coloca o leitor a parte do respeito que Jeanne tem pela sua antiga amiga de orfanato e como essa personagem possibilitou sua nova vida ao pedir que se casasse com o primo Simon. Baseado em seu discurso, depreendemos que a

\footnotetext{
${ }^{19}$ Nossa tradução: "Nicolas, você agradeceu o capitão pelo presente? Mantenha o cachorro próximo de você."

${ }^{20}$ Nossa tradução: "Deus me guarde, ele resmungou. Eu casei com uma fera."

${ }^{21}$ Nossa tradução: "Quando tivermos outra filha, ela será batizada como Marie, em sua homenagem. E as próximas serão Marguerite, Anne e Geneviéve. Oh, eu tenho muito trabalho pela frente."
} 
protagonista da diegese corrobora a versão historiográfica do fato apresentado por Zug (2016, p. 43), que explica o desejo do governo por famílias numerosas.

Já a personagem secundária, Marie du Voyer, praticamente desaparece do romance após cumprir sua tarefa de se casar com um colonizador, pois o foco do romance se centraliza nas aventuras da protagonista. Sobre a experiência de Marie du Voyer na colônia canadense quase nada sabemos. No fim do discurso romanesco, a protagonista escrevelhe uma carta, contando-lhe sobre sua vida e família, na qual ela apenas escreve saber sobre o fato que, embora o marido de Marie esteja prosperando, ela deseja retornar para a França.

Como essa narrativa canadense mescla história e ficção, faz-se necessário apresentar algumas informações sobre as diferentes fases do gênero romance histórico - que são três, segundo os estudos de Fleck (2007) - para uma melhor compreensão do modo como a autora lida com a inserção do material histórico na diegese romanesca.

A primeira delas, a fase acrítica, descrita pelo pesquisador no texto "A conquista do 'entre-lugar': a trajetória do romance histórico na América” (2007, p. 150-152), há duas modalidades: o clássico scottiano e o tradicional, que dele deriva. Ambos possuem suas origens ancoradas no romantismo europeu. Enquanto que no modelo do escocês Walter Scott, a questão histórica é vista apenas como um pano de fundo e volta-se para as ações das personagens ficcionais e suas aventuras, na modalidade tradicional, em geral, temos um relato ficcional que se alinha aos preceitos da história hegemônica para exaltar e glorificar aqueles que foram considerados heróis do passado.

$\mathrm{Na}$ segunda fase, crítica e desconstrucionista, desse gênero, encontramos as modalidades dos novos romances históricos e das metaficções historiográficas: narrativas na qual se busca a distorção dos materiais históricos ao incorporá-los na escrita ficcional pelo emprego de histórias alternativas. Há nelas o uso da autorreferencialidade, da paródia, da carnavalização, da intertextualidade, da ironia, dialogia, polifonia, e alguns outros recursos que proporcionam novas perspectivas com relação aos eventos do passado e a consciência de que tanto história como ficção são discursos, produtos de linguagem.

Por último, na terceira e mais atual fase, denominada "mediadora" pelo pesquisador, temos a modalidade do romance histórico contemporâneo de mediação que amalgama a grande maioria dos romances híbridos mais recentes. Nessa modalidade, conforme explicita Fleck (2007 p. 162), mostra-se uma conciliação entre as modalidades antecedentes. Nela não se renuncia aos processos que constituem as características essenciais do novo romance histórico latino-americano, como a paródia e toda a sinfonia bakhtiniana, mas o texto volta a ser mais linear, como nos modelos tradicionais, uma vez que o emprego das estratégias desconstrucionistas tende a ser mais moderado. É a mais recente modalidade detectada sobre o gênero romance histórico.

Ao analisar criticamente a narrativa híbrida The King's Danghter (2011), considerando esse conteúdo crítico sobre o gênero romance histórico e sua trajetória evolutiva, percebemos que ela se insere na terceira fase, a mediadora, e que sua configuração é típica dos romances históricos contemporâneos de mediação. Essa modalidade está difundida 
na mais atual obra de Gilmei Francisco Fleck, O romance histórico contemporâneo de mediação: entre a tradição e o desconstrucionismo - releituras críticas da história pela ficção (2017).

Nesse sentido, vemos que, em primeiro lugar, o pesquisador menciona que o romance histórico contemporâneo de mediação "constitui-se em uma releitura crítica do passado [e que] a nova tendência mantém, contudo, o intento da construção da verossimilhança [...].” (FLECK, 2017, p. 109). Acerca disso, o narrador heterodiegético exibe uma versão diferenciada da vinda das "filhas do rei" para a Nova França, indicando as dificuldades enfrentadas pelas jovens francesas na colônia canadense durante o século XVII. O discurso romanesco também confere um tom de autenticidade sobre os eventos históricos narrados na obra de Suzanne Martel, avalizados pela perspectiva que o relato adota de revelar a vivência das mulheres no contexto da colonização.

Em segundo lugar, conforme Fleck (2017, p. 110), nessa modalidade a leitura ficcional do passado apresentado "busca seguir a linearidade cronológica dos eventos na diegese, fixando-se neles para assegurar o avanço da narrativa." Segundo o pesquisador, essa volta da linearidade, que era deixada de lado nas modalidades desconstrucionistas o novo romance histórico latino-americano e a metaficção historiográfica -, está diretamente relacionada ao tipo de leitor menos experiente nas leituras de romance histórico. O romance The King's Daughter (2011) reproduz os eventos vivenciados pelas personagens de forma linear, pois descreve a saída do orfanato na França, a difícil travessia marítima, a chegada à colônia ultramarina, o casamento, a adaptação no novo território com ênfase no inverno rigoroso e na produção de alimentos para sobreviver nas florestas -, os ataques realizados pelos nativos Iroqueses e a gravidez de Jeanne. A maneira como a ficcionista elenca os eventos narrativos contribui para uma leitura mais fluida àquele leitor com menos prática na compreensão do discurso crítico.

Em terceiro lugar, Fleck (2017, p. 110) explica que o foco narrativo do romance histórico contemporâneo de mediação compartilha os propósitos da nova história, "pois privilegia visões a partir das margens, sem centrar-se nas grandes personagens da história como fazem muitos novos romances históricos e algumas metaficções historiográficas." (FLECK, 2017, p. 110). Na narrativa em estudo, temos os relatos de um narrador heterodiegético que apresenta outro prisma - o das personagens configuradas como "filhas do rei" - a ser averiguado em relação a colonização do Canadá. Aquele discurso oficial, que cimentava as tensões com um discurso distenso, é colocado de lado e a visão de uma personagem órfã, obrigada a assumir um papel de mãe e esposa, é posto em evidência.

De acordo com Peter Burke em "Abertura: a nova história, seu passado e seu futuro" (1992, p.12), os historiadores acreditavam que a história era uma narrativa de acontecimentos enquanto que a nova história se preocupava mais como as estruturas eram analisadas. Assim, a história tradicional, amplamente difundida pelos detentores do poder e da palavra, ofertava "uma visão de cima, no sentido de que [se concentrava] nos grandes feitos dos homens, estadistas, generais ou ocasionalmente eclesiásticos. Ao resto da humanidade foi destinado um papel secundário no drama da história." (BURKE, 1992, p. 12). Com o passar do tempo vários novos historiadores passaram a se dedicar a outros pontos de vista da história, "com as opiniões das pessoas comuns e com sua experiência 
da mudança social.” (BURKE, 1992, p. 13). Conforme o autor, a história da cultura popular é colocada em evidência; e assim surge a história vista de baixo.

Segundo Jim Sharpe, em "A história vista de baixo" (1992), esse tipo de relato, de pessoas antes consideradas comuns e que foram marginalizadas, tem o objetivo de "servir como um corretivo à história da elite" (SHARPE, 1992, p. 53) e oferecer "uma abordagem alternativa" (SHARPE, 1992, p. 53). Tais discursos possibilitam "uma síntese mais rica da compreensão histórica, de uma fusão da história da experiência do cotidiano das pessoas com a temática dos tipos mais tradicionais da história." (SHARPE, 1992, p. 54). Dessa forma, o ponto de vista apresentado pela protagonista Jeanne Chatel faz parte de uma tendência da "nova história", aquela considerada como vista de baixo. Antes era uma excluída e marginalizada, mas agora, torna-se presente e atuante na história com seu prisma sendo colocado em evidência.

Em quarto lugar, o pesquisador Fleck (2017, p. 110-111) explicita que

[...] o romance histórico contemporâneo de mediação prima pelo emprego de uma linguagem simples e de uso cotidiano, em oposição ao barroquismo e o experimentalismo linguístico dos novos romances históricos [...]. As frases são, geralmente, curtas e elaboradas de preferência em ordem direta, e com um vocabulário mais voltado ao domínio comum que ao erudito.

Um pouco adiante, ele explica que as obras também focalizam o processo narrativo e, em muitos casos, modernizam a linguagem do tempo passado, aproximando-a da linguagem de seus leitores. Na narrativa The King's Daughter (2011) encontramos uma escrita em nível de inglês intermediário com nuances para um nível avançado, porém com frases cujo léxico é mais simples e suas frases são curtas, como, por exemplo, "Did you build your fort? ?22 (MARTEL, 2011, p. 191). Embora a autora da obra retrate uma época do século XVII, sua linguagem mostra-se bem atualizada.

Em quinto lugar, Fleck (2017, p. 111) menciona que recursos bakhtinianos, como a dialogia, a polifonia, a intertextualidade e a paródia também podem estar presentes, mas que o uso do recurso escritural desconstrucionista nessa modalidade é bastante moderado. A partir dessas especificidades, observamos como o narrador heterodiegético utiliza a paródia para retratar a inversão de papéis vivenciados pelas “filhas do rei”. Elas passam da posição de moças altivas, de linhagem real, para fardos e são condicionadas à sombra de seu marido, procriando o máximo possível para satisfazer a Coroa Francesa. Conforme o discurso romanesco, "a woman anywhere else but in her house was a burden, an unnecessary risk, as inevitable responsibility."23 (MARTEL, 2011, p. 183). Nenhum recurso escritural empregado ridiculariza, caricaturiza, carnavaliza qualquer personagem ou situação, não constituindo-se essa narrativa num modelo de novo romance histórico, menos ainda de metaficção historiográfica. Contudo o discurso romanesco é crítico em relação ao discurso historiográfico que se fixa nos sujeitos masculinos e suas realizações

${ }^{22}$ Nossa tradução: "V ocê construiu seu forte?"

${ }^{23}$ Nossa tradução: "Uma mulher que não estivesse em casa era um fardo, um risco desencessário, uma responsabilidade inevitável." 
conquistadoras na colônia. Além da figura das "filhas do rei" parodiadas, depreendemos que a intertextualidade ocorre, também, devido ao contexto histórico presente na narrativa híbrida. É a França colonizando outro território, a Nova França - o atual Canadá - e as "filhas do rei" sendo enviadas como noivas para os colonizadores franceses, que estavam a serviço do rei, durante o século XVII.

A sexta e última característica do romance histórico contemporâneo de mediação é a "utilização de recursos metanarrativos, ou comentários do narrador sobre o processo de produção da obra." (Fleck, 2017, p. 111). Observamos que essa última característica não está presente na narrativa híbrida, contudo, todas as outras são bem visíveis e passíveis de comprovação.

\section{CONSIDERAÇÕES FINAIS}

A narrativa híbrida The King's Daughter (2011), da canadense Suzanne Martel, entrecruza história e ficção para abordar um tema que ficou relegado à margem: mulheres que tiveram um papel essencial na colonização do atual Canadá. A vinda dessas "filhas do rei" foi essencial para o desenvolvimento da terra recém-descoberta, pois, sem as mesmas, muitos dos colonizadores teriam se unido com as nativas ou teriam regressado à França, aspectos históricos que o romance aborda e relê criticamente. Com a chegada dessas mulheres, assegurou-se o território e o povoamento do local aumentou. Na narrativa fictícia, as personagens configuradas como Jeanne Chatel e Marie du Voyer, casam-se conforme o esperado, cumprindo, assim, seu papel. A protagonista, inclusive, torna-se mãe e tem a intenção de gerar mais crianças, ajudando no aumento da população canadense - aspectos que o romance reitera desde o discurso historiográfico.

A obra em estudo apresenta um tempo cronológico fiel ao evento ocorrido na historiografia, pois, enquanto que a escrita hegemônica apresenta o maior fluxo de vinda dessas moças entre 1663 e 1673, no romance a vinda das personagens, Jeanne Chatel e Marie du Voyer, ocorre em 1672 e narra-se sua estadia até 1674. O espaço geográfico também é fidedigno ao atual Canadá. Os locais Quebec e Ville-Marie, a atual Montreal descritos como espaços ficcionais da obra -, existiram e ainda estão presentes na geografia canadense atual.

Depreendemos que, ao mesmo tempo em que o discurso ficcional se aproxima do historiográfico, ele também apresenta outro prisma. A ótica da personagem aponta para uma releitura, que, "pela literatura, deixa de estar à margem e ressurge continuamente para novas interpretações, considerações e reflexões sobre o que, de fato, chega a nós como passado: um discurso construído a partir da seleção da ótica do poder." (ALBUQUERQUE; FLECK, 2015, p. 6). A historiografia não difundiu as dificuldades enfrentadas por essas mulheres, como o frio, a ausência de matérias primas e alimentos, a falta de hospitais e a distância entre um lugar e outro. Mesmo estando ciente do processo de desenvolvimento, ainda por acontecer, as personagens configuradas como "filhas do rei" eram surpreendidas pela falta de recursos e o modo como eram obrigadas a se adaptarem ao novo contexto no qual lhes era imposto viver. 
Depreendemos, ainda, que a saga de Jeanne Chatel e de Marie du Voyer, órfãs retratadas como "filhas do rei", reaviva o tema da inserção da mulher europeia no Canadá e evidencia a contribuição daquelas que foram deixadas de lado pelo discurso histórico de cunho masculino. Com tal ampliação das perspectivas sobre possíveis fatos e acontecimentos ocorridos na colônia, temos a chance de conhecer outra vertente para os acontecimentos do passado, apresentados pela obra The King's Daughter (2011), um romance histórico contemporâneo de mediação.

\section{REFERÊNCIAS}

ALBUQUERQUE, A. B.; FLECK, G. F. Canudos: conflitos além da guerra - entre o multiperspectivismo de Vargas Llosa (1981) e a mediação de Aleilton Fonseca (2009). Curitiba: CRV, 2015.

BURKE, P. Abertura: a nova história, seu passado e seu futuro. In: BURKE, P. A escrita da história: novas perspectivas. Tradução: Magda Lopes. São Paulo: UNESP, 1992. p. 7-38.

FLECK, G. F. A conquista do "entre-lugar": a trajetória do romance histórico na América. Gragoatá, Niterói, v. 12, n. 23, p. 149-167, 2. sem. 2007.

FLECK, G. F. O romance histórico contemporâneo de mediação: entre a tradição e o desconstrucionismo - releituras críticas da história pela ficção. Curitiba: CRV, 2017.

MARTEL, S. The king's Daughter. 8. ed. Toronto: Groundwood, 2011.

ROSENFELD, A. Literatura e personagem. In: CANDIDO, A. [et al.]. A personagem de ficção. São Paulo: Perspectiva, 2007. p. 9-50.

RUNYAN, A. K. Daughters of the king and founders of a nation: les filles du roi in New France. 2010. 101 páginas. Dissertação (Mestrado em Artes) - University of North Texas, Denton, 2010.

SHARPE, J. A história vista de baixo. In: BURKE, P. A escrita da história: novas perspectivas. Tradução: Magda Lopes. São Paulo: UNESP, 1992. p. 39-62.

TROUCHE, A. América: história e ficção. Niterói: EdUff, 2006.

ZUG, M. A. Buying a bride: an engaging history of mail-order matches. New York: New York University Press, 2016.

Recebido em: 05/05/2018

Aprovado em: 20/09/2018

Publicado em: 01/12/2018 